\title{
Use of Laser Acupuncture in Chronic Tensional Headache: Randomized Clinical Trial
}

\section{Uso do Laser Acupuntura na Cefaleia Tensional Crônica: Ensaio Clínico Randomizado}

\author{
Rafaela Gulhak Moretto ${ }^{\mathrm{a}}$ T Thais Schemberger Favarin ${ }^{\mathrm{a}}$; Morgana Neves ${ }^{\mathrm{b}}$; Paula Renata Olegini Vasconcellos ${ }^{\mathrm{b}}$; \\ Gladson Ricardo Flor Bertolini ${ }^{\mathrm{b}}$
}

\author{
aUniversidade Estadual do Oeste do Paraná, Physiotherapy Course. PR, Brazil.

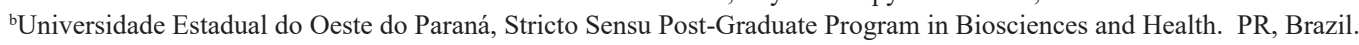 \\ *E-mail: gladsonricardo@gmail.com
}

\begin{abstract}
Since tension headache, besides being highly prevalent, has a deleterious effect on daily activities, the search for therapeutic resources is interesting. Thus, the objective of this study was to verify the effect of laser acupuncture in individuals with chronic tensional headache. The sample consisted of 14 volunteers with chronic tensional headache, separated into a control group (placebo) and an intervention group (laser acupuncture, $660 \mathrm{~nm}, 10 \mathrm{~J} / \mathrm{cm}^{2}$ ), in both groups the pen was positioned for 20 seconds in each of the six acupuncture points. There were three therapies on alternate days, and at the end there was previous evaluation by both the Visual Analog Pain Scale and the Headache Impact Test questionnaire. In both forms of evaluation there were significant differences in the comparison between evaluations, with reduction of values $(p<0.001)$, but without differences between groups or interaction $(p>0.05)$. It was concluded that the acupuncture laser showed no greater effectiveness than the placebo.
\end{abstract}

Keywords: Tension-Type Headache. Acupuncture Points. Meridians.

\section{Resumo}

Visto que a cefaleia tensional, além de apresentar alta prevalência, tem um efeito deletério sobre as atividades diárias, apresenta-se interessante a busca por recursos terapêuticos. Desta forma, o objetivo deste estudo foi verificar o efeito do laser acupuntura em indivíduos com cefaleia tensional crônica. A amostra foi composta por 14 voluntários, com cefaleia tensional crônica, separados em grupo controle (placebo) e grupo intervenção (laser acupuntura, $660 \mathrm{~nm}, 10 \mathrm{~J} / \mathrm{cm}^{2}$ ), em ambos os grupos a caneta foi posicionada por 20 segundos em cada um dos seis pontos de acupuntura. Foram três terapias em dias alternados, sendo que houve avaliação prévia e ao final delas tanto pela Escala Visual Analógica de Dor quanto pelo questionário Headache Impact Test. Em ambas as formas de avaliação houve diferenças significativas na comparação entre avaliações, com redução dos valores $(p<0,001)$, porém sem diferenças entre os grupos ou interação $(p>0,05)$. Conclui-se que o laser acupuntura não mostrou eficácia superior ao placebo.

Palavras-chave: Cefaleia do Tipo Tensional. Pontos de Acupuntura. Meridianos.

\section{Introduction}

Headaches are considered a public health problem, classified as debilitating disorders and, in some cases, make routine actions impossible, causing a great personal and social impact. Despite regional variations, headaches are a worldwide distribution problem involving people from all regions, ages, races and economic level ${ }^{1,2}$

One of the most frequent forms of headache is the socalled tension headache, or tension headache, generated by contraction of the cervical muscles, which can be caused by emotional stress. The increase in these muscle contractions increases circulating catecholamine levels, which in turn act causing muscles fiber contraction ${ }^{3.4}$. It is characterized by the constrictive character, usually bilateral, from mild to moderate intensity, not aggravated by routine physical activities and with variable duration between 30 minutes and 7 days ${ }^{5}$. ${ }^{6}$ Considered a frequent complaint among young students, pain implies disability, educational failure and school absenteeism on average between two and eight days a year, also bringing greater vulnerability to comorbidities and damage to quality of life.

A treatment option and traditional Chinese Medicine, being acupuncture one of several therapeutic modalities ${ }^{7}$. It has few adverse effects, and can be used to treat a variety of conditions, such as inflammatory diseases and chronic pain ${ }^{8}$. An application technique that has gained use is acupuncture with low-power laser', which is a form of noninvasive bio stimulation, presents itself as an attractive alternative because it consists of a fast treatment with low infection risk. Laser acupuncture is the combination of the two therapeutic modalities, acupuncture and low-power laser, which promote the stimulation of traditional acupuncture points with lowpower laser irradiation ${ }^{10}$. The use of laser associated with acupuncture points is considered ideal for cases where techniques with traditional needles are not indicated, as in very sensitive persons or with coagulation problems ${ }^{11}$. 
Before the impact that chronic tension headache has on the social, psychological and physical scope of students, it is important to investigate ways to alleviate the pain and negative effects that headache have on the individual's daily journey ${ }^{6}$. Moreover, it is common for the relief of tension headache to occur to demand analgesic drugs, which can provide several side effects ${ }^{12}$. ${ }^{13,14}$ On the other hand, acupuncture laser treatment is a non-invasive technique, with no evidence of side effects, but it still needs proofs. Thus, the objective of this study was to verify the effect of acupuncture laser on individuals with chronic tension headache, students from a public university.

\section{Material and Methods}

The present study is characterized as a randomized, blind clinical trial by the patient, registered with the Brazilian Register of Clinical trials (RBR-9YDDRG), after approval by the Research Ethics Committee of Universidade Estadual do Oeste do Paraná (UNIOESTE), under number 3.286.687.

The research was carried out at UNIOESTE physical
Rehabilitation Center, with a sample of 14 volunteers, but one volunteer did not perform all the procedures and was excluded from both genders (two men and 11 women), sedentary students, students of UNIOESTE, aged between 18 and 30 years $(21.1 \pm 1.9$ years $)$ and that presented symptoms of chronic tensional headache, according to the International Headache Society. Individuals with headache with distinct origins of tension were excluded from the study, those who were under any type of treatment were also discarded, and individuals with other disorders of the neuromusculoskeletal system were excluded from the study.

The sample was randomly divided into two groups, intervention group (IG) and control group (CG). CG was submitted to direct contact of the laser pen, however without the radiation emission. GI received treatment with low-power active laser, the equipment had a power of $30 \mathrm{~mW}$ (measured prior to the start of visits), a wavelength of $660 \mathrm{~nm}$, a power density of $10 \mathrm{~J} / \mathrm{cm}^{2}$, a spot area of $0.06 \mathrm{~cm}^{2}$, application time of 20 seconds in each of the six acupuncture points (Table 1).

Table 1 - Characteristics of the Acupuncture Points

\begin{tabular}{|l|l|l|}
\hline \multicolumn{1}{|c|}{ Point } & \multicolumn{1}{|c|}{ Location } & \multicolumn{1}{|c|}{ Indication } \\
\hline Hegu (IG4) & $\begin{array}{l}\text { dorsal side of the hand, between the first and second metacarpal bone in the } \\
\text { middle of the first dorsal interosseous muscle; when opening the thumb and } \\
\text { index finger, in the middle of the line between the junction of the first and } \\
\text { second metacarpal bone, the middle point of the palm edge, or when closing } \\
\text { hand, between the first and second metacarpal, the highest point on top of the } \\
\text { interosseous muscle. }\end{array}$ & $\begin{array}{l}\text { headache, arm and shoulder pain, } \\
\text { insomnia, nervousness, among others. }\end{array}$ \\
\hline Quchi (IG11) & $\begin{array}{l}\text { radial side of the elbow, at the brachioradial muscle; when bending the elbow, } \\
\text { on the radial depression at the end of the cubital line. }\end{array}$ & $\begin{array}{l}\text { headache, red and painful eyes, } \\
\text { psychosis, among others. }\end{array}$ \\
\hline $\begin{array}{l}\text { Schenmen } \\
\text { (C7) }\end{array}$ & $\begin{array}{l}\text { ulnar side of the wrist, on the radial side of the tendon of the ulnar carpal } \\
\text { flexor muscle, behind the pisiform bone. }\end{array}$ & $\begin{array}{l}\text { psychoneurosis, anxiety, palpitation, } \\
\text { headache and dizziness, insomnia, } \\
\text { among others. }\end{array}$ \\
\hline $\begin{array}{l}\text { Fengchi } \\
\text { (VB20) }\end{array}$ & $\begin{array}{l}\text { below the occipital edge in the depression between the trapezium and } \\
\text { sternocleidomastoid muscles, on the edge of the hair. }\end{array}$ & $\begin{array}{l}\text { headache, stiffness and pain in the } \\
\text { neck, dizziness, vertigo, migraine, } \\
\text { insomnia, among others. }\end{array}$ \\
\hline $\begin{array}{l}\text { Taichong } \\
\text { (F3) }\end{array}$ & $\begin{array}{l}\text { between the first and second metatarsals, behind the metatarsal-phalangeal } \\
\text { joints. }\end{array}$ & headache, dizziness, among others. \\
\hline $\begin{array}{l}\text { Ying-Tang } \\
\text { (Ext5) }\end{array}$ & in the middle of the line between the eyebrows. & $\begin{array}{l}\text { frontal headache, dizziness, vertigo, } \\
\text { insomnia, hypertension, } \\
\text { others. }\end{array}$ \\
\hline Source: among
\end{tabular}

For the proposed therapeutic form, three interventions were performed with each volunteer, with one day interval between them. The application always began, according to traditional Chinese Medicine, from inferior to superior, in men from left to right, in women from right to left, following this same order in all the interventions performed.

Before the first intervention and immediately after the last one, it was sought to analyze the pain signals with two evaluation instruments. To quantify the intensity of chronic tensional headache, it was used through the pain Visual Analog scale (VAS), with increasing variation, according to pain intensity, from zero to ten.

The HIT-6 questionnaire (Headache impact Test) was also applied $^{16}$, which aims to evaluate the impact of headaches on quality of life in all social spheres, it has a scoring system that classifies how much headaches affect the days and functionality of the individual. The higher the total points the greater the impact of headache on the individual's life. The total HIT-6 score ranges from 36 to 78 points and, through it, four levels of headache impact can be characterized: Little or no impact: 38 to 49 points; Some impact: 50 to 55 points; Substantial impact: 56 to 59 points; Very severe impact: 60 or more points.

The data were presented as mean and standard deviation and analyzed using the SPSS 20.0 program by mixed generalized models, with a significance level of $5 \%$. 


\section{Results and Discussion}

In the analysis of the pain signs using the analogue visual scale (EVA), it was found that there was no significant difference among the groups $(p=0.407)$, but there was significant difference among between the values, AV1 and AV2 $(p<0.001)$, and there was no interaction between the groups and evaluations $(\mathrm{p}=0.337)$.

In assessing the impact of tensioning headache on quality of life using the HIT- 6 tool, it was found that there was no significant difference between the groups $(p=0.370)$, but there was a significant difference between the assessments $(p<0.001)$. There was also no significant difference in the interaction between groups and evaluations $(\mathrm{p}=0.302)$ (Table 2).

Table 2 - Data from the EVA and HIT-6 evaluations for the different groups (GC and GI), in both evaluations (AV1 and AV2).

\begin{tabular}{|l|c|c|c|c|}
\hline & \multicolumn{2}{|c|}{ EVA } & \multicolumn{2}{c|}{ HIT-6 } \\
\hline & AV1 $^{\text {A }}$ & AV2 $^{\text {B }}$ & AV1 $^{\text {A }}$ & AV2 $^{\text {B }}$ \\
\hline GC & $6.7 \pm 1.0$ & $1.7 \pm 1.6$ & $65.2 \pm 2.3$ & $49.2 \pm 3.5$ \\
\hline GI & $5.0 \pm 2.4$ & $1.3 \pm 1.5$ & $64.9 \pm 2.7$ & $52.6 \pm 8.5$ \\
\hline
\end{tabular}

Data expressed as mean and standard deviation. Equal capital letters represent statistical similarity.

Source: Research data.

In this study, values were reduced for both forms of evaluation, however, this characteristic occurred both for the treated group and for the control group. The sample studied was of convenience, that is, they joined the study because they complied with posters and advertisements in social media and of the 13 individuals who carried out the entire protocol of evaluations and treatment/simulation, 11 were female. This fact coincides with the study by Fernandes et al. ${ }^{17}$, who also observed a greater number of women than that of men, and quote that they present a higher number of recurrent pain, including headaches. Such occurrence may be related to estrogen and progesterone hormones, which increases stress response, an important factor for such type of headache ${ }^{18}$.

According to Braga et al. ${ }^{6}$, the proportion of students who reported impairment in daily activities (concentration capacity, mood, relationships with other people, cognitive abilities, psychomotor skills and performance of practical and evaluation activities) due to headache being higher than those who reported impairment due to other types of pain. In the present study, it was verified that the sample presented a pain sign of tension headache with changes in quality of life, evaluated by the tool HIT6, with values that had a very severe impact, and in the final evaluation were qualified with little impact or some impact, respectively, in CG and GI. Although there are no statistically significant differences between the groups, only between evaluations, the results indicated that there was possibly a placebo effect.

Eleven volunteers presented symptoms such as pain without prior warning, installation of slow onset, location ranging from frontal, middle of head, head or whole head, and may be bilateral, heavy, "agonized" and sometimes poorly defined, but it was hardly unilateral and latent. Moreover, light, smells, head movements did not usually worsen pain and were not accompanied by sickness or vomiting. Whereas in the study by Pizzo et al. ${ }^{19}$, all of the sample referred unilateral pain, from moderate to strong intensity, constant, daily and lasting 6 to 12 hours a day, beginning in the region of occipital nerves spreading to the frontal and temporal regions.

Huang et al. ${ }^{13}$ in an article with an overview of systematic reviews, they point out that the use of acupuncture seems to be a form of effective treatment for tensional headaches, however, they report that of the 36 articles evaluated, only seven presented high evidence quality. Since there are cases in which the use of the needle is not indicated, the possibility of using the acupuncture laser form arises, which is performed to stimulate the traditional points of this technique ${ }^{11}$. Gottschling et al. $^{20}$ assessed the use of acupuncture laser in children with headache, both tension and migraine, treatment was individualized according to traditional Chinese Medicine standards. They used a wavelength of $830 \mathrm{~nm}, 30 \mathrm{~mW}$ and irradiance of $3.8 \mathrm{~W} / \mathrm{cm}^{2}$, and observed that the active laser was superior to the placebo group.

The parameters used in the present study were wavelength of $660 \mathrm{~nm}$, energy density of $10 \mathrm{~J} / \mathrm{cm}^{2}$ and power of $30 \mathrm{~mW}$, with application duration of 20 seconds per point, and the points were standardized in all the volunteers and were not individualized according to initial evaluation. Whereas in the study by Ebneshahidi et al. ${ }^{21 \mathrm{LI} 4, \mathrm{~GB} 14, \text { and GB20 bilaterally. Points were irradiated }}$ for 43 seconds, and the intensity was $1.3 \mathrm{~J}(13 \mathrm{~J} / \mathrm{cm} 2$, an $830 \mathrm{~nm}$ device was used, with a power density of $13 \mathrm{~J} / \mathrm{cm}^{2}$, irradiance of $39 \mathrm{~mW} / \mathrm{cm}^{2}$, with 43 seconds of application per point. The authors report a significant reduction in tensional headache, which may have occurred due to the different application parameters, since laser actions are dependent on several factors, such as wavelength. According to $\mathrm{Smith}^{22}$, infrared radiation skips the photochemical events of cytochrome $\mathrm{C}$ oxidase and activates the calcium channels for their photophysical effects on the membranes, while those within the visible red wavelength produce effects from absorption in the mitochondria.

Headache is an interfering factor in daily life activities, a cause of absenteeism in different tasks and is directly linked to stress situations and management of the same $e^{23,24}$. Pain is a multidimensional parameter, which does not involve only the intensity of physical stimuli, but psychosocial and neurosensorial characteristics, passing by modulations in the central nervous system, resulting in the ultimate experience of pain. Its intensity corroborates previous experiences related to pain stimuli, feelings, pain control, cultural factors, anxiety and understanding of the situation that causes pain ${ }^{25}$. Thus, the placebo effect can occur easily when using therapeutic resources, depending on the individual's belief that such a resource will be useful to him or her, as defended for the effects of acupuncture by Solomon ${ }^{26}$, even more considering that even without the use of needles the pressure made by laser 
pen contact occurred at the same points of the active group.

It is suggested that new research on the use of low-power laser should be carried out, considering some limitations presented in this study, such as the small sample number, the absence of a control group without intervention, considering the strong relationship with the psychological aspect that tension headache has, and also different irradiation parameters.

\section{Conclusion}

It is concluded that acupuncture laser has not shown analgesic efficacy or improved negative repercussions on academic life, in the tensional headache, higher than placebo.

\section{References}

1. Rizzoli P, Mullally WJ. Headache. Am J Med 2018;131(1):1724. doi: 10.1016/j.amjmed.2017.09.005.

2. Cruz MC, Cruz LC, Cruz MCC da, Camargo RP de. Cefaleia do tipo tensional: revisão de literatura. Arch Heal Investig 2017;6(2):53-8. doi: 10.21270/archi.v6i2.1778.

3. Jensen RH. Tension-type headache: the normal and most prevalent headache. Headache 2018;58(2):339-45. doi: 10.1111/head.13067.

4. Dao JM, Qubty W. Headache diagnosis in children and adolescents. Curr Pain Headache Rep 2018;22(3):17. doi: 10.1007/s11916-018-0675-7.

5. Matta AP da C, Moreira Filho PF. Cefaléia do tipo tensional episódica: Avaliação clínica de 50 pacientes. Arq Neuropsiquiatr 2006;64(1):95-9. doi: 10.1590/S0004282X2006000100019.

6. Braga P cristina V, Souza LAF, Evangelista RA, Pereira LV. The occurrence of headaches and their effect upon nursing undergraduate students. Rev Esc Enferm USP 2012;46(1):133-9. doi: 10.1590/S0080-62342012000100019.

7. Ren Y, Li H, Wang Y, Chen Y. Report of guidelines for diagnosis and treatment of common internal diseases in Chinese medicine: Headache. J Evid Based Med 2020;19;13(1):70-80. doi: 10.1111/jebm.12378.

8. Zijlstra FJ, van den Berg-de Lange I, Huygen FJPM, Klein J. Anti-inflammatory actions of acupuncture. Mediators Inflamm 2003;12(2):59-69. doi: 10.1080/0962935031000114943.

9. Madani A, Ahrari F, Fallahrastegar A, Daghestani N. A randomized clinical trial comparing the efficacy of low-level laser therapy (LLLT) and laser acupuncture therapy (LAT) in patients with temporomandibular disorders. Lasers Med Sci 2020;35(1):181-92. doi: 10.1007/s10103-019-02837-x.

10. Oliveira RF, Freitas PM. Laser therapy on points of acupuncture on nerve repair. Neural Regen Res 2016;11(4):557. doi: 10.4103/1673-5374.180734.

11. Valente C, Gomara FL, Marques Neto PL, Souza RC. Aplicações do laser na acupuntura. Cad Naturol Ter Complement 2015;4(6):47-54. doi: 10.19177/cntc. v4e6201547-54.

12. González-Hernández A, Marichal-Cancino BA, Maassen Van Den Brink A, Villalón CM. Side effects associated with current and prospective antimigraine pharmacotherapies. Expert Opin Drug Metab Toxicol 2018;14(1):25-41. doi: 10.1080/17425255.2018.1416097.

13. Huang J, Shen M, Qin X, Guo W, Li H. Acupuncture for the treatment of tension-type headache: An overview of systematic reviews. Evidence-based Complement Altern Med 2020;2020. doi: 10.1155/2020/4262910.

14. Baxter GD, Bleakley C, McDonough S. Clinical effectiveness of laser acupuncture: a systematic review. JAMS 2008;1(2):65-82. doi: 10.1016/S2005-2901(09)60026-1.

15. Wen TS. Acupuntura clássica chinesa. São Paulo: Cultrix; 1985.

16. Yang M, Rendas-Baum R, Varon SF, Kosinski M. Validation of the Headache Impact Test (HIT- $6^{\mathrm{TM}}$ ) across episodic and chronic migraine. Cephalalgia 2011;31(3):357-67. doi: 10.1177/0333102410379890.

17. Fernandes DV, Viana FS, Cardoso JP. Comparative study between manual therapy and TENS Burst in patients with tension-type cephalalgia. Fisioter Mov 2015;28(2):327-37. doi: 10.1590/0103-5150.028.002.ao13.

18. Bernardi MT, Bussadori SK, Porta K, Fernandes S, BiasottoGonzalez DA, Fernandes KPS, et al. Correlação entre estresse e cefaléia tensional. Fisioter Mov 2008;21(1):87-93.

19. Campi R, Pizzo DA, Bordini CA. O efeito do laser de baixa intensidade no tratamento das cefaleias cervicogênicas. Apresentação de sete casos. Rev Dor 2010;11(1):94-100.

20. Gottschling S, Meyer S, Gribova I, Distler L, Berrang J, Gortner L, et al. Laser acupuncture in children with headache: a double-blind, randomized, bicenter, placebo-controlled trial. Pain. 2008;137(2):405-12. doi: 10.1016/j.pain.2007.10.004.

21. Ebneshahidi NS, Heshmatipour M, Moghaddami A, Eghtesadi-Araghi P. The effects of laser acupuncture on chronic tension headache: a randomised controlled trial. Acupunct Med 2005;23(1):13-8. doi: 10.1136/aim.23.1.13

22. Smith KC. Molecular targets for low level light therapy. Laser Ther 2010;19(3):135-42. doi: 10.5978/islsm.19.135.

23. Lima AS, Araújo RC, Gomes MRA, Almeida LR, Souza GFF, Cunha SB, et al. Prevalência de cefaleia e sua interferência nas atividades de vida diária em adolescentes escolares do sexo feminino. J Paul Pediatr 2014;32(2):256-61. doi: 10.1590/0103-0582201432212113.

24. Silva LCS, Freitas BJSA. Influência dietética e nutricional na migrânea. J Heal Sci 2016;18(1):63-9. doi: 10.17921/2447-8938.2016v18n1p64-73.

25. Silva JA da, Ribeiro-filho NP. A dor como um problema psicofísico. Rev Dor 2011;12(2):138-51. doi: 10.1590/ S1806-00132011000200011.

26. Solomon S. Acupuncture for headache. It's still all placebo. Headache 2017;57(1):143-6. doi: 10.1111/head.12975 